\title{
Performance of patch repairs on historic concrete structures: a preliminary assessment
}

\author{
Ana Paula Arato Gonçalves ${ }^{1, *}$, Susan Macdonald ${ }^{1}$, Élisabeth Marie-Victoire ${ }^{2}$, Myriam Bouichou ${ }^{2}$, and Chris Wood $^{3}$ \\ ${ }^{1}$ Getty Conservation Institute, 1200 Getty Center Drive, Suite 700, Los Angeles, CA, USA \\ ${ }^{2}$ Laboratoire de Recherche des Monuments Historiques, 29 rue de Paris, 77420 - Champs-sur-Marne, France \\ ${ }^{3}$ Historic England, 4th Floor, Cannon Bridge House, 25 Dowgate Hill, London, EC4R 2YA, UK
}

\begin{abstract}
Carrying out patch repairs to historic concrete buildings and structures needs to be done carefully if their cultural value and significance is to be maintained. This often means repairs using custom designed materials and mixes for compatibility with the original concrete, and with great care paid to good workmanship. But with most repairs, commercial mixes are used which are not compatible with the host concrete but are justified because they adhere well, cure quickly and require limited skills to implement. A research collaboration has been established to test the performance of both approaches. The Performance Evaluation of Patch Repairs on Historic Concrete Structures (PEPS) began in 2018 and is a collaboration between the Getty Conservation Institute, Historic England and the Laboratoire de Recherche des Monuments Historiques. Its purpose is also to better understand key design and specification parameters and application methods. The research is based on assessing case studies in USA, England and France within a variety of climatic and environmental conditions, typologies and repair materials. This paper will present the methodology adopted to evaluate the repairs in the first phase. This will also include historical research on the specification and application of the repairs, preliminary field assessment and some testing.
\end{abstract}

\section{Introduction}

As the building stock of the $20^{\text {th }}$ century ages, more examples from that era are now being appreciated and identified as culturally significant. With this recognition comes a need for well understood repair strategies that better meet some of the typical principles applied to work on historic buildings and a body of practitioners who are able to specify and undertake this work. The importance and dominance of reinforced concrete as a construction material during the $20^{\text {th }}$ century has left us with a diverse, creative and innovative concrete heritage. Today there is increasing interest and urgency in the development of sympathetic repair approaches and materials that can meet conservation demands.

The rapid development of reinforced concrete construction over the $20^{\text {th }}$ century means that much of this concrete heritage, however carefully designed and built, did not benefit from the current level of knowledge about material behavior and durability that contemporary construction employs. Consequently, some of these structures were repaired at an early stage, bolstering the parallel development of the concrete repair industry. Nowadays, this multi-billion-dollar industry is supported by prolific research and professional organizations. However, though concrete conservation is a discrete subsection of the much larger concrete repair industry, it is still in its infancy and there remains much work to be done to adequately equip this nascent field with the knowledge and skills to meet the growing demands.

\section{Challenges in conserving historic concrete}

The fundamental difference between concrete conservation and concrete repair is that any work targeting historic structures must prioritize the need to preserve its cultural significance [1]. Therefore, the development of a repair strategy for a historic concrete structure has to consider the cultural values supported by that material, such as aesthetic value in the case of an exposed concrete façade. Once the cultural significance of a structure is identified, typical conservation principles should be applied to ensure that its significance is transmitted to future generations. These principles include minimal intervention and minimizing risks by fully understanding the long-term effects of adopted repair materials and methods.

Despite the difference in principles, the methodologies used to develop appropriate repairs for ordinary reinforced concrete structures and for the conservation of culturally significant reinforced concrete share the same basic framework. Best-practice for both should base decision-making on a thorough analysis of the causes of damage, which includes the history of the building, past repairs, field and laboratory based scientific analysis. The

\footnotetext{
Corresponding author: anaratogoncalves@getty.edu
} 
design of the repair strategy has to take into consideration compatibility of the repair material to the substrate. In addition, the repair method of choice has to be appropriate for the type of repair and the available means, in terms of economy, availability of materials and workmanship. In all cases, the specified solution should be durable and satisfy all the performance criteria stablished for the structure.

The common roots shared by these two fields make it possible to adapt a lot of the materials and techniques developed for repair of ordinary structures to historic concrete. However, some of the biggest challenges relate to the use of standard repairs used on conservation projects, particularly the durability of patch repairs designed to preserve the aesthetic significance of the original concrete [2-4]. This knowledge gap is reflected in American [2, 5, 6] and European [7] concrete repair standards, which mention color and texture as properties to consider in specific cases, but fail to give specific information on how this can be achieved or measured successfully. It was also found that data on repair methods and materials contain little or no information about their effects on the appearance of the patch. In addition, almost no information was found on how these repairs age. Although durability of repairs is an ongoing concern in the concrete repair industry, long-term appearance, patina, and re-repair, are issues considered primarily by the conservation field.

Another challenge is that conservation principles promote the use of like-for-like materials to avoid the risks of introducing new materials into a system. Additionally, a conservation approach refrains from using materials and techniques that have not been through the test of time. However, materials such as polymer modified cement-based mortars and concretes, bonding agents, corrosion inhibitors, and various additives are widely used in the concrete repair industry to improve workability of the material, performance, and compatibility between the behavior of the new and the old materials. However useful, their long-term effects on behavior and aesthetic of the repair should be understood before being applied on historic structures.

Due to this preference for custom-designed repair materials, in addition to the inherent difficulty of matching final repair color and texture to original exposed concrete, the task of repairing historic exposed concrete requires an extremely high level of craftsmanship and quality control. Developing solutions is also highly specialized, as it requires professionals with experience in both concrete repair and conservation. Currently, the necessary skilled professionals are rare in most parts of the world.

An important contributing factor to this situation is the lack of literature and training opportunities focused on concrete conservation. The existing literature focuses on providing basic guidance on concrete conservation based on experience $[4,8,9]$, and, more rarely, on scientific research [10, 11]. Practical challenges in developing repair solutions are found in articles and a few books that present isolated case studies [12]. Moreover, practitioners report different approaches being used to patch repair historic concrete with varying degrees of success.

However, there are no specific studies on the longterm performance of patch repairs designed to preserve the aesthetic significance of the original concrete. Research originated in the concrete repair field does not consider the same performance criteria as the conservation field, therefore the data is useful as a reference but results are not directly applicable.

An experts meeting held by the Getty Conservation Institute in 2014 concluded that one of the main research priorities for concrete conservation was patch repair materials and methods specifically focused on providing better guidance to practitioners [13]. However, this would have to be based on an evaluation of past repairs to understand current approaches and the conditions for successful application when related to their long-term performance.

\section{Performance evaluation of patch repairs on historic concrete structures (PEPS)}

As a response to this specific challenge, three institutions, the Getty Conservation Institute (GCI), Historic England (HE) and Laboratoire de Recherche des Monuments Historiques (LRMH) are collaborating in the development of a research project called the Performance Evaluation of Patch Repairs on Historic Concrete Structures (PEPS). The goal is obviously to evaluate the performance of patch repairs on exposed concrete in historic structures and buildings in order to better understand the key design and specification parameters and application methods required for a successful conservation approach. The aim is to produce practical guidance that will help those repairing historic concrete. As government agencies faced with providing advice to stewards of historic buildings, both LRMH and HE have been working for many years on many of the challenges of concrete conservation and now have a body of monitored research undertaken over many years that can help to inform this work.

The scope of the project includes the preliminary evaluation of thirty case studies, ten case studies in each country participating in this study: England, France, and the USA. Case studies were selected according to the following criteria:

- Concrete buildings or structures, where the surface is exposed or untreated;

- Repairs performed with the goal of conserving historic and aesthetic values;

- Access to documentation, and professionals who worked on the repair (architects, engineers, tradesmen and craftsmen);

- $\quad$ Easy access to the site and patches to be evaluated; 
- Consent must be given from site owners/managers for access to site and data;

- Case studies should have diverse ages of parent concrete and ages of repair;

- Include repairs made with various levels of craftsmanship;

- Include repairs that used different materials (concrete, mortar, like-for-like, industrialized, etc.) and placement techniques (hand troweled, poured);

- Case studies can present combined use of patch repairs and other protection or treatment techniques;

- Complementary techniques applied should not obscure patches, such as coatings;

- Case studies should represent a good range of environmental conditions (coastal, urban...) and aspects.

The case studies will not be identified in articles and any other public dissemination unless otherwise agreed by site owners. A very wide range of case studies were selected in order to reflect the breadth of current approaches and the diversity of contexts for concrete repairs. The range of different materials, applications and sites, also means that it will not be possible to compare performance results between case studies. However, given the current lack of literature on the subject, there is significant value in developing benchmarking research that shows the current state of concrete conservation in relation to patch repairs. It is expected that results will indicate the need for future research in specific aspects and repair materials.

Patch repairs are defined as surface repairs with limited or no load bearing function. This focus was defined by the omnipresence of this type of intervention in concrete conservation. Complementary treatment techniques such as cathodic protection, realkalisation, penetrating water repellants, etc., will not be the focus of the assessment, but their influence on patches will be evaluated if they are present in any case studies.

The methodology developed consists of a preliminary evaluation and a later phase of in-depth study. The first phase comprises evaluation of all thirty case studies, which includes desk studies on building specifications and documentation undertaken during repair, complemented by conducting interviews with owners, asset managers or other relevant individuals to validate the history of the repair. This data will be used to understand how the repairs were developed and executed to support interpretation of current conditions observed on site. This phase also includes field assessments of each case study with the goal of documenting and evaluating the current state of the patch repairs through a visual survey, photography, condition mapping, and in-situ nondestructive evaluation techniques, such as sound and covermeter testing. The aim is to assess ten patches in each case study chosen as representative patches in various conditions and degrees of exposure. This phase is being conducted by the three teams, one in each country, and data is collected in forms before being transferred into a database. Using different assessment teams poses the challenge of maintaining a manageable degree of variance in data collection. This is achieved by ensuring frequent contact, constant sharing of results, and the collaboration of all in the development of the methodology, and trials.

The results of the first phase are expected to identify the different approaches currently being used in the repair of historic concrete and indicate issues that might appear over time. The analysis of these results will inform final planning and fine-tuning of the methodology for the second phase of evaluations. In addition, results will be used as base for the selection of the fifteen case studies for the in-depth study.

In order to assess the patch repairs beyond their surface appearance, the second phase of evaluation will include in-depth study and testing of five sites per country. Due to the historic and aesthetic values of the surfaces investigated, priority will be given to nondestructive in situ testing, but these results will be complemented with laboratory analysis to improve results' reliability. The goal of this phase of investigation is to detect underlying deterioration and identification of material characteristics that could help understand the conditions identified and the behavior of the repair. Testing will be performed on the same patches assessed on the previous phase and their adjacent areas as it is important to identify material characteristics to detect any significant differences in behavior between repair and concrete substrate. Samples from all three countries may be sent to the same laboratory to guarantee consistent results in the analysis. The testing program is still under development.

\section{Planned outcomes from the research and next steps}

Ultimately, this project intends to produce better understanding on:

- Current repair methods and practices;

- $\quad$ performance of patch repairs typically undertaken on historic concrete;

- efficacy and durability of patch repair materials currently used in historic concrete;

- efficacy of current repair methods.

A long-term goal of the work is to develop and disseminate best practice information to those involved in conserving historic concrete including:

- Guidance on selection of appropriate repair mortars;

- Practical guidance on repair methods;

- A methodology for recording, monitoring and evaluating repairs to historic reinforced concrete.

Additionally, these results will also help in the identification of specific future research needs.

The research project began in 2018 and the first phase of work will be undertaken in 2019, with later phases 
planned in 2020. The project will provide updates of the work at regular milestones.

\section{References}

1. H. A. Heinemann, H. Zijlstra, and R. P. J. van Hees. Concrete Solutions 2011. Grantham. Schneck, Mechtcherine (Eds), 55-67. CRC Press (2012)

2. American Concrete Institute Committee 546. ACI 546.3R-06 guide for the selection of materials for the repair of concrete. In Concrete Repair Manual, American Concrete Institute, Farmington Hills, MI; International Concrete Repair Institute, Des Plaines, IL, pp. 881-914 (2008)

3. S. Macdonald (ed). Concrete: Building Pathology. Oxford: Blackwell Science (2003)

4. D. Odgers (ed). Concrete Practical Building Conservation. London: Ashgate (2012)

5. American Concrete Institute Committee 562. ACI 562-16 Code Requirements for Assessment, Repair, and Rehabilitation of Existing Concrete Structures and Commentary, Reported by ACI Committee 562. Farmington Hills, MI: American Concrete Institute (2018)

6. American Concrete Institute Committee 563. ACI 563-18: Specifications for Repair of Concrete in Buildings, Reported by ACI Committee 563. Farmington Hills, MI: American Concrete Institute (2018)

7. British Standard Institution. BS EN 1504 Products and Systems for the Protection and Repair of Concrete Structures- Definitions- RequirementsQuality Control and Evaluation of Conformity- Parts 1 to 10. London, UK: British Standard Institution (2005-2017)

8. P. E. Gaudette, and D. Slaton. Preservation of Historic Concrete. Preservation Briefs 15. Washington, DC: National Park Service, Heritage Preservation Services https://www.nps.gov/tps/how-topreserve/preservedocs/preservationbriefs/15Preserve-Brief-Concrete.pdf.

9. D. Farrell, and C. Wood. Concrete Repairs: Traditional Methods and Like for Like Repairs. In The Building Conservation Directory: Tisbury: Cathedral Communications (2015)

10. E. Marie-Victoire. Les alterations visibles du béton: Définitions et aide au diagnostic. Les cahiers techniques du Cercle des Partenaires du Patrimoine, no. 1. Champs-Sur-Marne: Cercle des Partenaires du Patrimoine (1996)

11. M. Bouichou, and E. Marie-Victoire. Le nettoyage des bétons anciens: Guide des techniques et aide à la décision. Les cahiers techniques du Cercle des Partenaires du Patrimoine, no. 4. Champs-SurMarne: Cercle des Partenaires du Patrimoine (2009)
12. C. Croft, S. Macdonald, and G. Ostergren (ed). Concrete: Case Studies in Conservation Practice. Los Angeles: Getty Publications (2019)

13. Custance-Baker, Alice and Susan Macdonald. Conserving Concrete Heritage Experts Meeting: The Getty Center, Los Angeles, California, June 911, 2014, Los Angeles, CA: Getty Conservation Institute, $\quad \mathrm{p} \quad 22 \quad$ (2015) http://www.getty.edu/conservation/publications_res ources/pdf_publications/pdf/Conserving_Concrete Heritage_Experts_Meeting.pdf 